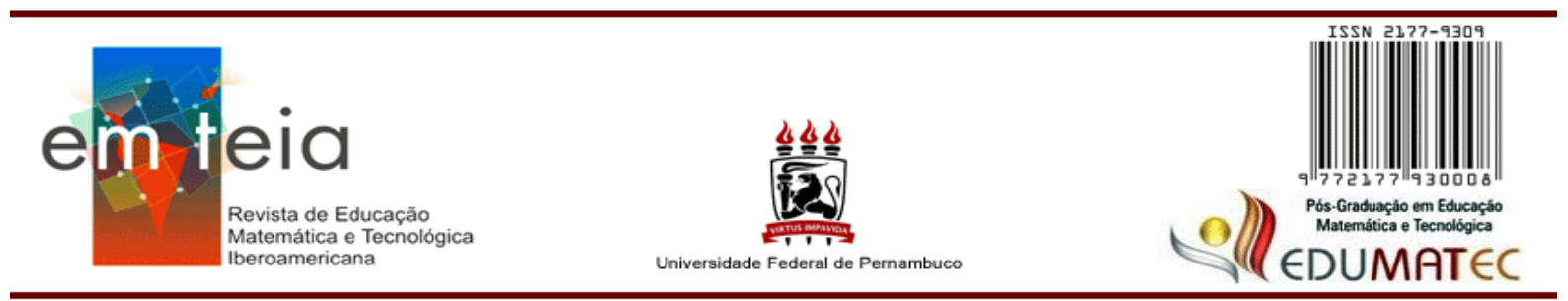

PROFESSOR-CRIANÇA:

\title{
UMA POSSIBILIDADE NA FORMAÇÃO DE PROFESSORES DE MATEMÁTICA
}

Teacher-child: a possibility in the education of mathematics teacher education

\author{
Fernanda de Abreu Lima \\ Mestranda em Ensino de Matemática \\ UFRGS - RS - Brasil \\ fernanda.fdal@gmail.com \\ Francisco Egger Moellwald \\ $\mathrm{PhD}$ em Educação Matemática \\ UFRGS - RS - Brasil \\ chico.egger@gmail.com
}

\section{Resumo}

Temos memórias de docências e discências, reconhecemos alguns modos de estar em sala de aula. Seguimos deveres, esquivamos devires. Mantemos uma relação com a verdade que muitas vezes inibe a experimentação e a criação de novos modos de estar em uma aula de matemática. Considerando as forças densas do contexto de verdades estabelecido sobre docência em Educação Matemática e, ao mesmo tempo, forçados a buscar outros modos de nos relacionarmos com esse contexto, propomos neste texto um exercício que explora a potência da Filosofia da Educação na formação do professor de matemática, sem intenção de explicar, legitimar ou consolidar, mas de explorar, "pensar, ser e ensinar de outro modo" (KOHAN, 2003, p. 225). Ousamos lidar com a preparação de um personagem, o professor-criança. Um personagem que talvez já exista, mesmo que adormecido, mesmo que com outros nomes, outras formas... Um personagem que se movimenta inspirado pelo conceito de devircriança e seu potencial na formação do professor de matemática. Uma preparação que tenta encontrar brechas para o novo e tornar-nos sensíveis a encontros intensivos e aos movimentos causados por suas forças.

Palavras-Chave: Devir-criança. Docência. Preparação. Formação. Verdade.

\begin{abstract}
We have memories of teaching and learning, we recognize ways of being in the classroom. We follow tasks, we dodge becomings. We keep a relation with the truth that often inhibits experimentation and creation of new ways of being in a math class. Considering the dense forces within the context of truths established around teaching in Math Education, and simultaneously forced to seek other ways of relating with this context, we propose in this text an exercise that explores the potency of Philosophy of Education for the education of the math teacher, without the intention of explaining, legitimating or consolidating, but exploring, "thinking, being and teaching in a different way" (KOHAN, 2003, p. 225). We thus dare to deal with the preparation of a character, the teacher-child. A character that may already exist, even if asleep, even with other names, other forms... A character that moves around inspired by the concept of becoming-child and its potential in the education of the math teacher. A preparation that seeks to find breaches for the new and make us become sensitive to intensive encounters and the movements caused by their forces.
\end{abstract}


Keywords: becoming-child, teaching, preparation, education, thruth.

\section{Introdução}

Desde muito cedo começamos a construir certa noção sobre docência. Quando iniciamos nossa vida escolar, enquanto alunos, já passamos a apreender alguns modos de estar em sala de aula, tanto como professores quanto como alunos. Modos que internalizamos e que podem ser acessados por meio de nossa memória, voluntária ou involuntariamente. Talvez alguns esquecimentos, aqueles que nos possibilitem olhar de outro modo para verdades já produzidas e memorizadas, possam contribuir para a experimentação e criação de outras docências/discências, visando, em nossas aulas de matemática, a coexistência daquelas em movimento contínuo.

Experimentação e criação são palavras que nos acompanham nesta escrita. E não queremos que se tornem pesadas ou que sejam percebidas como obrigações. Consideramos que existem possibilidades para criar na docência, mas não supomos que devemos perceber tal ato como um objetivo; criação escapa de planejamentos e métodos, escapa da nossa vontade. Supomos apenas que alguns modos de estar no mundo podem potencializá-la como possibilidade. Já o termo experimentação, que neste texto refere-se a esses modos, foi utilizado no sentido de ousar olhar para fora do internalizado, de arriscar-se a novidades, de perscrutar a nós mesmos e ao que parece naturalmente verdadeiro no ambiente escolar, tentar o diferente, escapar da linearidade dos métodos para permitir improvisos e outros caminhos ainda não pensados. Se assim sentir-se bem o professor.

Deste modo começamos explorando, por meio dos estudos de Rodrigues e Schwantz (2016), alguns dos aspectos que se referem a forças próprias de contextos de verdade(s) produzidos e institucionalizados como verdadeiros na docência, os quais buscam definir "o" legítimo, "o" correto, "a" realidade. E buscamos alternativas que potencializem outras docências. Constitui-se essa busca como um exercício de Filosofia da Educação, que, conforme caracteriza Kohan (2003), não pretende explicar, legitimar ou consolidar, mas "permite-nos pensar, ser e ensinar de outro modo" (p. 225). Trata-se, portanto, de um exercício capaz de promover movimentos na formação do docente em Educação Matemática.

Nesta busca, nos afastamos das forças daquilo que é dito de senso comum e da cristalização de certos modos de ser professor para pensarmos, mesmo que por meio de uma breve exploração, a potência do conceito devir-criança na formação do professor. Explicitamente, este texto se constitui como um exercício que explora ressonâncias da Filosofia da Educação na Educação Matemática. 
A motivação para o presente texto surgiu através dos estudos desenvolvidos durante a disciplina Ressonâncias Filosóficas e Educação Matemática ${ }^{1}$, pois uma nova forma de lidar no lugar do desgaste, no lugar das normas e definições, no lugar do "tu deves", o grande dragão de Nietzsche-Zaratustra (NIETZSCHE, 2005).

\section{Docência circular: algumas considerações sobre este contexto de verdade(s)}

Parece-nos que somos involuntariamente inseridos em certos contextos, os quais produzem, afirmam e reafirmam sua(s) verdade(s). Basta olharmos para uma criança. Logo que nasce, essa criança passa a ser exposta a diversas informações, já começa a ser inserida, mesmo antes de seu nascimento, em certo contexto de verdades. Durante a infância nos esquivamos inocentemente dessas forças, mas aos poucos as marcas desse contexto passam a se fortalecer e uma relação com tais verdades se estabelece. Uma relação na qual somos receptores e não criadores, na qual a verdade é considerada preexistente, uma descrição da realidade para esse contexto.

Da mesma maneira, algumas marcas que caracterizam certos modos de docência começam, desde muito cedo, a ganhar suas formas. Internalizamos alguns dos modos de agir de nossos professores de matemática, seja da escola básica, seja da graduação. Internalizamos ditos de senso comum a respeito da prática docente. Há um contexto de verdades cristalizado sobre alguns dos modos de estar em uma aula de matemática. Algo que talvez possa ser estendido à escola, de um modo geral.

E embora os programas de graduação busquem incentivar outros modos de docência no âmbito da Educação Matemática, parece haver uma tendência em "seguir o fluxo" e em recorrer à memória. Quando o professor inicia suas atividades no ambiente escolar é possível que essas verdades internalizadas, combinadas com as que circundam o referido contexto, falem mais alto e se manifestem nos seus modos de estar em sala de aula. Modos que contribuem para a manutenção do contexto de verdades já produzido e legitimado pelo e para o ambiente escolar.

Em um estudo realizado por Rodrigues e Schwantz (2016), na Universidade Federal de Pelotas, com alunos do curso de Licenciatura em Matemática em fase de estágio supervisionado, foi observada essa tendência, destacando-se três fatores, considerados buracos negros na formação do professor de matemática: autoritarismo, docência circular e

\footnotetext{
${ }^{1}$ Disciplina do Programa de Pós-graduação em Ensino de Matemática - Universidade Federal do Rio Grande do Sul, preparada e conduzida pelo Professor Francisco Egger Moellwald.
} 
avaliação punitiva (p. 944). Como o nome sugere, através do sentido atribuído pela Física, são fatores pelos quais se perde a potência de produzir novos modos de docência/discência, que acaba sendo sugada pelas forças dos modos de agir já cristalizados na imagem que costuma ser atribuída ao professor de Matemática. Imagem, produzida política e historicamente, de um mestre que se reveste da autoridade do conhecimento intelectual.

Autoritarismo e avaliação punitiva constituem-se por ações do docente em sala de aula. Poderíamos dizer que se manifestam na tentativa de ser mantido certo controle comportamental, modos de agir não recentes que passam como uma herança, ações que foram memorizadas pelos alunos que fomos e hoje, muitas vezes, emergem nos professores que nos tornamos. Não pretendemos estender a exploração destes dois fatores, pois nos parecem, de certo modo, consequentes do outro buraco negro, a docência circular.

$\mathrm{Na}$ docência circular pretendemos nos aprofundar um pouco mais, pois este buraco negro remete à manutenção de uma relação "que atribui ao pensamento o amor natural do verdadeiro e à verdade a determinação explícita daquilo que é naturalmente pensado" (DELEUZE, 2003, p. 17). "Naturalmente pensado" constitui uma expressão que nos remete à reminiscência e não ao pensamento. Pensar envolve encontros intensivos e buscas às quais esses podem nos forçar. Um encontro com algo "que pode, de repente, extrapolar nosso quadro de referências habituais, fazendo-nos sentir a força daquilo que, embora não se manifeste no imediatamente dado, insiste nele e agita em nós percepções e sensações estranhas, ou seja, novas" (NASCIMENTO, 2012, p. 25).

Para caracterizar esse buraco negro, chamado docência circular, Rodrigues e Schwantz (2016) apresentam um breve percurso histórico. Percurso esse que passa pelo Eu penso de Descartes e pelos ideais iluministas. Ambos remetem à ideia de método, a um amor natural pela verdade e à pressuposição de uma boa vontade do pensamento em encontrá-la (DELEUZE, 2003). Movimentos que reverberam em nossos modos de ser e de estar no mundo, trazendo à tona o sujeito da informação, do saber, do método.

\footnotetext{
"Eu concebo, eu julgo, eu imagino, eu percebo" - assim nos ensinou o Cogito a produzir aquilo que somos e o que estamos em vias de ser: uma pessoa cartesiana, isto é, um docente cartesiano que passa a anular a capacidade de duvidar em prol do uso de um método fixado no seu pensamento (RODRIGUES; SCHWANTZ, 2016, p. 947).
}

Em nossa leitura, autoritarismo e avaliação punitiva passam a ser percebidos como consequentes da docência circular. Estas ações parecem surgir quando recorremos à memória para atender necessidades instituídas por um contexto, por um método, por um planejamento 
pré-fixado. Avaliação constitui um meio de punir o aluno que não atendeu às expectativas e autoritarismo um comportamento que tenta forçar o aluno a participar e a interagir do modo esperado. Quando nos fechamos em métodos tendemos a colocar certos ideais à frente, produzindo uma aula que se move em função do resultado esperado, ignorando aquilo que escapa, aquilo que difere.

Muitas vezes caímos na docência circular, seguimos o fluxo, nos fixamos no que já está dado, recorremos apenas à memória. Por vezes trocamos o método, os referenciais, as opiniões, mas seguimos dependentes de uma verdade denominada socialmente como verdadeira. Uma tentativa de troca que tem sua importância, e que não deve ser desvalorizada. Percebemos essa tentativa como uma manifestação da vontade do professor em buscar certa diferença. Tais trocas constituem um movimento que se mostra desafiador, que exige coragem. E talvez, por trazer consigo uma carga considerável de contratempos e de novos enfrentamentos, torna-se possível que essa vontade se dissolva ante a força das verdades já produzidas e internalizadas. O que nos leva a supor a importância em não nos atermos apenas à substituição de padrões; afinal o ato de nos fixarmos e nos fecharmos neles parece ser um dos fatores que constituem o buraco negro da docência circular. Talvez, do modo como a educação escolar se configura hoje, em alguns momentos seja preciso recorrer a certos padrões. Não há necessidade de abolir tudo que foi feito até hoje e recomeçar do zero, também não há necessidade de nos fixarmos nesses padrões.

O que fazer então? Sendo a docência circular um buraco negro, quais possibilidades restariam? Ao atribuir um sentido filosófico a essa expressão, assim como sugerido em Rodrigues e Schwantz (2016), podemos considerar a existência de possibilidades e de potencialidades. Do improvável podem surgir forças para a criação, para experimentar o diferente. Podemos considerar que uma saída se constitua ao nos deixarmos cair nesse buraco negro, ao buscarmos forças para dele sair e ao nos permitirmos a ele retornar, tantas vezes quantas forem necessárias. Não sabemos se há uma saída definitiva da docência circular, mas, ao invés de tentarmos encontrar e fixar uma saída, podemos considerar a coexistência de diferentes modos de docência/discência em uma aula de matemática, algo que talvez nos ajude nesse movimento.

Um movimento que se constitui quando nos colocamos na condição de aprendizes, quando bagunçamos o reconhecido e nos expomos ao desconhecido. Algo como nos soltarmos da relação que concebe uma verdade como dada, passível apenas de reconhecimento, cuja busca constitui-se unicamente através de métodos. Em Deleuze (2003), 
outra relação se torna possível: "A verdade nunca é o produto de uma boa vontade prévia, mas o resultado de uma violência sobre o pensamento" (p. 15).

Com boa vontade reconhecemos verdades já produzidas em seus respectivos contextos, reconhecemos contextos de verdade(s) produzidos para a docência, memorizamos alguns, estudamos outros. Tal boa vontade faz parte da formação do professor e não supomos sua extinção, mas aqui estamos em busca de outra relação que possa coexistir com o que já está produzido. Segundo Deleuze (2003), a verdade não depende de um método, "a verdade depende de um encontro com alguma coisa que nos força a pensar e a procurar o que é verdadeiro" (p. 15). Verdade, neste sentido, não é algo dado e fixado, apenas reconhecível e memoriável, mas sim algo por vir e em movimento. Algo que, para aquele que a busca, pode ser dita a verdade, verdade que resulta de sua busca. Verdade que se solta do artigo definido "a" quando considerada no coletivo, passando a combinar com o artigo indefinido "uma". E isto não invalida as verdades já produzidas. Reconhecê-las torna-se tão necessário quanto não nos mantermos fixados a elas.

\section{Devir-Criança}

Os devires se fazem por encontros afetivos em um mapa de intensidades, disjunção inclusiva. Depois de se desfazer da norma, depois de deixar o peso do "tu deves" para trás, nasce a criança

(TRINDADE, 2016).

Passamos agora a uma breve exploração do conceito devir-criança, conceito criado por Deleuze e Guattari, que nos provoca inspiração nesta escrita. E talvez seja melhor começar escrevendo sobre o que não the diz respeito. Não se trata de um retorno à infância, não significa ser infantil, tampouco agir como uma criança, imitando seus modos de estar no mundo. Devir é da ordem dos acontecimentos, dos encontros, de um tempo de intensidades, Aión.

“Devir é uma antimemória” (DELEUZE; GUATTARI, 2012, p. 96), força para a criação, força para que uma linha deixe de submeter-se a pontos pré-fixados, fazendo outros movimentos até então impensados. Força para transitar por uma linha que não se constitui pela substituição do legitimado pelo não legitimado, movimento que levaria à futura legitimação do que hoje é não legitimado. Linha que não se encontra nesta troca de submissões, mas sim entre elas. Uma fuga que se faz sem sair do lugar, sempre diferença. Possibilidades para outras docências e discências coexistirem entre a docência circular e as 
novidades. "Um devir não é um nem dois, nem relação de dois, mas entre-dois, fronteira ou linha de fuga, de queda, perpendicular aos dois" (p. 96).

Possibilidade para escapar do legitimado, do senso-comum, da opinião, daquilo que já está consolidado na estrutura em que nos encontramos, inclusive em nós mesmos, em nossa memória. "O devir-criança é uma forma de encontro que marca uma linha de fuga a transitar, aberta, intensa" (KOHAN, 2004a, p. 64). Não um encontro qualquer, como encontrar um amigo, mesmo que ao acaso, ou algum objeto perdido no bolso de um casaco. Também não se caracteriza como um encontro grandioso, planejado e esperado, mas sim um encontro intensivo. "O que nos precipita num devir pode ser qualquer coisa, a mais inesperada, a mais insignificante" (DELEUZE; GUATTARI, 2012, p. 93).

Por meio desses encontros, que são alheios à nossa vontade, pode surgir potência para nos desfazermos das forças do memorizado e do reconhecido para arriscarmos o desconhecido. Embora sejamos, com frequência, instigados a nos esquivar deles e a preservar o que já está produzido no contexto de verdades ao qual supostamente pertencemos, neste caso, o escolar, esses encontros nos interessam, pois neles há potência para a novidade, para a criação, para que o encantamento surja ou ressurja nas aulas de matemática.

Devir-criança, movimento cheio de imprecisões e de indecidibilidades. Que não se caracteriza por um agir de modo inconsequente, imprudente, infantil. Que não significa negar padrões e verdades já estabelecidas. Talvez movimento que busque explorar vizinhanças entre o memorizado/reconhecido e a novidade de modo descompromissado, sem colocar verdades à frente. Um explorar que provoca uma fuga da relação que coloca verdades como pontos préfixados. Relação que se desfaz na criança do devir-criança.

Assim, a criança do devir-criança não é um sujeito nem um objeto da educação, mas uma figura da alteridade, isto é, o Outrem que expressa um mundo possível para as formas de viver e pensar a educação. A criança, enquanto devir-criança ilimitado, que se introduz na educação, é condição de possibilidade de outra educação porque é um modo de experimentar o advento de outra educação possível (JÓDAR; GÓMEZ, 2002, p. 35).

\section{Preparando um personagem: o professor-criança}

Considerando as forças densas do contexto de verdades estabelecido sobre docência em Educação Matemática e, ao mesmo tempo, nos sentindo forçados a buscar outros modos de nos relacionarmos com essas verdades, ousamos lidar com a preparação de um personagem, o professor-criança. Personagem que talvez já exista, mesmo que adormecido, 
mesmo que com outros nomes, outras formas... Um personagem que se movimenta através da inspiração provocada pelo conceito devir-criança, que nos remete ao professor que questiona e desafia o "tu deves", que se permite experimentar outras docências.

De acordo com Deleuze e Guattari (2012, p. 93), “de uma certa maneira, é sempre 'homem' que é o sujeito de um devir; mas ele só é um tal sujeito, ao entrar num devirminoritário que o arranca de sua identidade maior". A representatividade homem constitui-se molar. Professor também pode ser percebido como tal representatividade. E a criança do professor-criança, uma minoria. $\mathrm{O}$ personagem professor-criança busca um movimento que visa à vulnerabilidade da identidade maior. Uma provocação que visa a sensibilizações. Um soltar-se e esquecer-se de tal identidade. Não um esquecimento absoluto, mas de alguns traços. Daqueles traços que resistem à aventura das experimentações.

Não há caracterização, nem falas, nem roteiro para a constituição deste personagem. No entanto, percebemos no exercício de "buscar-se enquanto professor" uma possível preparação para o movimento que possibilita a atuação do professor-criança. Trata-se aqui de um buscar-se que difere do conhecer-se a si mesmo de Sócrates. Um buscar-se na perspectiva de Foucault, que, segundo Kohan (2004b, p. 127), "inverte a posição do filósofo socrático: a curiosidade filosófica não busca aumentar o conhecimento de si, mas, ao contrário, desaproximar-se do que se conhece sobre si mesmo". Desaproximar-se, pois talvez reconheçamos apenas memórias e certezas advindas de alguns contextos de verdade(s), em relação aos quais temos uma sensação de pertencimento.

"Buscar-se como professor seria evitar legitimar o que se sabe e o lugar que se ocupa. Poderia ser perder-se no que não se pensa, no que não se sabe, jogar outro jogo de verdade daquele que se está participando" (KOHAN, 2004b, p. 129). Buscar o professor de matemática que somos requer então abrir mão de certas opiniões e certezas, abandonar justificativas que mantenham e reforcem o legitimado. Requer perguntar pelos porquês desses modos de docência/discência, observar os possíveis efeitos do que estamos sendo e experimentar outros modos. Requer que nos observemos de longe, que nos estrangeirizemos do nosso próprio mundo para tentar vê-lo com outros olhos, com olhos que tenham a potência de uma criança. Um buscar-se que não tem um ponto de chegada em vista e que se faz em movimento não linear.

Buscar espaços para o personagem professor-criança. Viver a sala de aula. Permitir-se sofrer desestabilizações. Sentir uma aula de matemática, ao invés de passar por ela como se a aula já estivesse pronta antes mesmo de começar, como se uma aula consistisse de um momento de oportunizar aprendizagens apenas aos alunos, como se a matemática escolar já 
estivesse esgotada e a única tarefa do professor fosse informar definições e exemplos. Enfim, experimentar. Mesmo as repetições.

Buscar-se enquanto docente que atua na Educação Matemática constitui um movimento capaz de dar vida a este personagem, uma possibilidade para nossa formação. Um movimento que passa entre o legitimado no sistema escolar e o que lhe é exterior. Um personagem que vive em busca de brechas para experimentar e criar outros modos de docência/discência, modos que, mesmo considerando métodos e verdades já dadas, não se fixem, modos que permitam aberturas à diferença.

Assim, sem supor substituições de uma verdade por outra, de um modo de docência por outro, o "desaproximar-se do que se conhece sobre si mesmo" (KOHAN, 2004b, p. 127) propõe um exercício que nos permite "desfazermo-nos não apenas desta ou daquela verdade, mas de certa relação com a verdade” (p. 129), um dos traços que mais nos imobiliza dentro de uma identidade maior. Esse desfazer-se nos instiga a perceber verdade como uma produção e não como algo dado. Como algo que comporta espaços propícios a esquecimentos, experimentações e criações, e não como algo prescritivo e descritivo.

Um desfazer-se que parece fundamental para a realização de movimentos, para que nosso personagem possa ganhar vida potencializando a possibilidade de criação e a experimentação de outros modos de docência e discência em Educação Matemática, bem como a coexistência desses. O próprio desfazer-se constitui um movimento importante. Pois desaproximar-nos do professor que representamos e daquilo que reconhecemos sobre docência potencializa a subtração de identidades maiores. Manifestar o professor-criança pode nos ajudar a enfraquecer o poder do "tu deves" que se abriga em nossa memória inibindo a criação e a experimentação.

\section{Considerações finais}

Há diversas maneiras de pensarmos a formação do professor de matemática. Considerar a presença e a preparação deste personagem, o professor-criança, surge de um exercício que se passa entre Educação Matemática e Filosofia da Educação. Um exercício movido por uma inquietação que vive buscando brechas para desaproximar-se do legitimado, e assim perguntar “O que estamos a fazer enquanto professores?”. Conforme nos ensina Foucault (1998, p. 13), "Existem momentos na vida onde a questão de saber se se pode pensar diferentemente do que se pensa, e perceber diferentemente do que se vê, é indispensável para continuar a olhar ou a refletir". 
Ao nos afastarmos daquilo que a priori conhecemos de nós mesmos, ao nos desfazermos de uma relação com a verdade, como algo fixado, capaz de definir, qualificar e delimitar nossos pensamentos e o modo como deciframos o mundo, ao nos tornarmos sensíveis ao insignificante e ao inesperado estamos nos preparando para que nosso personagem, o professor-criança, possa entrar em cena com suas indagações e piruetas, com seus esquecimentos e suas curiosidades, com ou sem alegorias e adereços, mas com sua potência para experimentar e, talvez, criar.

Trata-se de um exercício importante para nós, professores de matemática, pois possivelmente em nossa formação inicial a noção de método como busca pela verdade tenha sido reforçada. Afinal "estamos acostumados a pensar a verdade do lado da ciência, do lado da demonstração, da prova, da regra, da lei, do estatuto, da argumentação, da aquiescência, da conformidade, da proposição" (KOHAN, 2004a, p. 57), o que possivelmente tem contribuído para que essa verdade seja percebida, de um modo geral, como algo dado, que valoriza a regulação em detrimento da alegria da experimentação e de uma possível criação, levando-nos a considerar que nossos pensamentos e ações serão adequados apenas quando daquela se aproximarem.

Com isso não buscamos invalidar verdades já produzidas. O que se sugere é um desfazer-se de uma relação que nos gere tristeza. E um experimentar que não necessariamente busque oposições, mas que perambule pelas vizinhanças do legitimado. Não supomos que esse desfazer-se, preparação para o advento de nosso personagem, constitua uma via para um movimento devir-criança. Trata-se de preparação inspirada neste conceito, não de certezas e de métodos. Encontros intensivos são imprevisíveis, não há ordem nem planejamento para nos encontrarmos com o inesperável, com o insignificante. No entanto, percebemos a preparação, o desfazer-se da relação que nos subjuga a um contexto de verdades, como um meio que potencializa sensibilizações a tais encontros e movimentos.

Se há potência para criar e experimentar antes da instauração dessa relação, há potência também quando algo começa a fazê-la ruir. Segundo Nietzsche (2005, p. 53) "Inocência, é a criança, e esquecimento; um novo começo, um jogo, uma roda que gira por si mesma, um movimento inicial". Para nascer a criança torna-se necessário desfazer-se do dragão "tu deves". Uma possibilidade para transvalorar a força dos ditos buracos negros em potência para um professor-criança, aquele que ousa experimentar "pensar, ser e ensinar de outro modo" (KOHAN, 2003, p. 225) e dizer "sim" ao seu potencial criador. 
REFERÊNCIAS

DELEUZE, G. Proust e os signos. 2. ed. trad. Antonio Piquet e Roberto Machado. Rio de Janeiro: Forense Universitária, 2003.

DELEUZE, G.; GUATTARI, F. Mil platôs: capitalismo e esquizofrenia, vol. 4. 2. ed. Trad. Suely Rolnik. São Paulo: Editora 34, 2012. (Coleção Trans).

FOUCAULT, M. História da sexualidade II: O uso dos prazeres. 8. ed. Trad. Maria Thereza da Costa Albuquerque. Rio de Janeiro: Graal, 1998.

JÓDAR, F.; GÓMEZ, L. Devir-criança: experimentar e explorar outra educação. Educação \& Realidade, Porto Alegre, v. 27, n. 2, p. 31-45. Jul/dez 2002.

KOHAN, W. O. Três lições de filosofia da Educação. Educação \& Sociedade, vol. 24, n. 82. p. 221-228, 2003. Disponível em: <http://dx.doi.org/10.1590/S0101-73302003000100012〉. Acesso em: 13 abr. 2018.

KOHAN, W. O. A infância da educação: o conceito devir-criança. In: Lugares da infância: filosofia. Rio de Janeiro: DP\&A, 2004a. p. 51-68. (Org.).

KOHAN, W. O. Sócrates e Foucault professores: entre o ensino do já sabido e a busca por ensinar diferentemente. In: GALLO, Sílvio; SOUZA, Regina Maria de (Orgs.). Educação do preconceito: ensaios sobre poder e resistência. Campinas, SP: Alínea, 2004b. p. 119-130

NASCIMENTO, R. Teoria dos signos no pensamento de Gilles Deleuze. 2012. 216p. Tese (Doutorado em Filosofia) - Universidade Estadual de Campinas, Campinas, 2012.

NIETZSCHE, F. Os discursos de Zaratustra - Das três metamorfoses. In: Assim falou Zaratustra: um livro para todos e para ninguém. Trad. Mário da Silva. 14. ed. Rio de Janeiro: Civilização Brasileira, 2005. p. 51-53.

RODRIGUES, C. G.; SCHWANTZ, J. W. Buracos Negros na Formação Inicial de Professores de Matemática. Bolema, Rio Claro, v. 30, n. 56, p. 939-953, dez. 2016. Disponível em: <http://dx.doi.org/10.1590/1980-4415v30n56a05 >. Acesso em: 13 abr. 2018.

TRINDADE, R. Devir-criança. Razão Inadequada. São Paulo. 2016. Disponível em: <https://razaoinadequada.com/2016/03/16/devir-crianca/>. Acesso em: 13 abr. 2018. 